\title{
Effective Factors of Diversified HR and Relationship Management: A Qualitative Case Study on TokyaTech, NY
}

\author{
Nadir Kolachi $1^{1}$ \\ ${ }^{1}$ Skyline University, University City of Sharjah, UAE \\ Correspondence: Nadir Kolachil, Skyline University, UAE. Tel: 00971-56-2642546. E-mail: \\ nadir.kolachi@gmail.com
}

Received: October 19, 2015

Accepted: November 1, 2015

Online Published: December 18, 2015

doi:10.5539/ijbm.v11n1p242

URL: http://dx.doi.org/10.5539/ijbm.v11n1p242

\begin{abstract}
This qualitative case study is specially drafted for the purpose of enhancing students' exposure on diversified HR and relationship Management. Modern age is the age of Human Resources and Relationship Management in order to have a corporate success in today's stiff competition. This case adopts an armchair case approach to discuss the required concept of HR \& Management and apply on an imaginary company mentioned in this case. The proposed frameworks in this Case study are the primary sources of authors and properly aligned to apply on the company mentioned in this case. This case holds 100 percent primary source for the purpose of clarity on HR \& Management diversity for Business graduates especially for HR \& Management subjects. The practical implication of this approach is beneficial for Business students \& Faculty to help students in understanding basic case approach and enhance the exposure to apply on any organization. This study covers the cultural and diversity issues around four sampled locations. The case proposes the solution with the help of descriptive models that are proposed to address the case situations in this paper.
\end{abstract}

Keywords: diversified HR, relationship management, TokyaTech

\section{Introduction}

TokyaTech is world's leading company that deals in telecom products. The company operates in twenty countries with 20000 employees at different levels. The company's success is mainly dependent on diversity management that allows to deal employees from varied cultural contexts. The company was established in year 2000 with a small head office in Manhattan and later spread over the world within just one decade to twenty destinations with huge success. The main decentralized units are London, Matera, Shanghai and Dubai. The company faces some issues related to diversity that are being controlled by International managers. TokyaTech had stiff competition in 2005 as they misinterpreted the effects of diversity. Employees were just hired but not trained according to the importance of diversity. This led company experiencing some turnover. Mr Chi Cork, a Harvard graduate took over as CEO and again maintained the same diversity activities but with exclusive feel of diversity importance to employees. Mr. Chi maintained a unanimous fit among employees that fostered more collaboration and started achieving good results. Mr. Ryan Chem, CTO is self-centered, very good employee but only collaborate if he wants to. He believes that company is only run because of his department and other departments are of no use. The business of TokyaTech is highly affected and the company has lost most of the customers especially in London, Matera, Shanghai and Dubai. Mr. Chi has got much pressure and plans to travel to the affected regions. He set a schedule to discuss with regional directors. He has a background of HR \& Marketing in his entire career. He has been very concern about HR \& Management departments since many years. In his tenure, he transformed HR department and branded marketing department based on customer \& employee friendly in US and other decentralized centers. He wants to improve on further concerns after his visits to all centers. He always bring change in every five years. He believes that HR department can function for many years in the same fashion but marketing department cannot function in same style for many years. He believes that marketing department should be changing at the diversified pace as customers can change their preferences in more developed fashion these days.

\section{Brief Literature Review}

Leadership with HR management becomes effective in managing people. Self-motivation \& leadership insight can influence others in most positive manner. As suggested by Sisson and Storey, 2000 "Top management, who 
make strategic decisions (including HRM strategic decisions), establish the organization's values and philosophy (Schuler \& Jackson, 1999) and influence its whole approach to managing people (Sisson \& Storey, 2000)". This shows the meaning of managing people and maintain values. In modern companies, motivation \& leadership are not behaviours but organization strategies that may help in building cordial atmosphere and organizational culture. Such management culture can lead everyone to put efforts and change behaviors. As Buller \& other philosophers (1998) argued that Organizational culture is one of the most important factors of the internal organizational environment that have a great bearing on SHRM (Buller, 1988; Truss \& Gratton, 1994; Gennard \& Kelly, 1995; Aryee, 1991). This makes organizations to follow and act as per the changes in employees' behavior and cultural contexts. Orienting people with motivational intent can bridge a cordial relationship management between employer and employees. Walton (1985) also points that the organization emphasizes joint problem solving and planning, and invests in developing harmonious relationships with employees (Walton, 1985; Arthur, 1992). This may help in organizational productivity. The HRM policies should be balanced with the benefits of employer and employees. The policies may not be bad to employees but becomes bad when employees are unaware. Proper orientation should be given to change employee behaviours and perceptions to work. As Kurland (1999) said that HRM systems, policies, and procedures that operate in an organization have been identified as impacting on an individual's perceptions of bias and fairness (Kurland \& Egan, 1999; Greenberg, 1990). Fair organization theory \& behavior towards employees may change employee behaviours towards organization and people will put more efforts for organizational productivity. Moorman (1991) also said that employees believe they are treated fairly in the workplace then they hold positive attitudes towards organization (Moorman, 1991). Organizational behavior is the main reason of organizational productivity. It must be addressed by HR managers and Leaders who can help all employees to adjust in the culture and promote organizational activities. As Muenjohn and Armstrong (2007) said that leadership styles and behaviors cannot be isolated from culture and hence it is one of the core elements that influence leadership style and approach. Further the belief should be instilled in employees as Shamir (1993) said that Transformational leaders transform the belief, commitment level and effort level of subordinates in the positive direction (Shamir, House and Arthur 1993).

\section{Visits to Decentralized Centers}

\subsection{Chi'S Visit (London)}

Andrew in London office had called a meeting and informed all employees about the arrival of Chi. Employees were unaware about Chi's visit. Andrew had just normal meeting not based on agenda but just a meeting to fill the document. Employees were smiling and turning their faces on the agenda. Employees asked about the growth plans but Andrew did not satisfy them. Chi on the other hand was excited but little nervous as well. He wanted to regain company position in all decentralized units. He kept writing brief notes on motivation and ownership that he planned to communicate. He expected that all employees might be waiting for him. On Monday morning, Chi reached to office. Andrew received him and had a breakfast and proceeded to conference room. While he was setting his slides in line, employees keep coming, Chi noticed that employees were not having any impression that Chi is going to tell them. Andrew welcomed Chi and formally started the meeting with the employees. Andrew presented the company position. Some of the employees were surprised and inquired about many things. This thing made Chi surprised why employees were unaware about the things they should be aware. Chi took part in the participation and started communicating the points on motivation and future plans of meeting. Some good changes in the company. Chi noticed that people were not clear about the things happening in the company. People were not properly aligned to set their targets. Employees were not taken into confidence. He imagined those all points while sitting in Business class of United Airline. He thought of some harsh decisions after his return to NY.

\subsection{Chi's Visit (Matera)}

Chi landed in Bari and took a taxi to Matera. He just did it on his own to keep the visit surprise and enjoy. From Bari to Matera he enjoyed the best sightseeing travelling and kept enjoying some donuts till he reached to the main historical city Matera. He also felt as he was part of the Oceans 12 that was filmed in Matera. Any way, he finally managed to reach in the hotel and dropped an email to Giovanni that he wants to see all employees tomorrow. Next morning he reached to the office and directly proceeded to board room to meet employees. Giovanni was supposed to give formal presentation but she just put all other people to explain what went wrong with the company. Employees were hesitant and little emotional while explaining the tings about the company. It seemed that there was pressure on employees and explained that all is good we told them. Most of the American companies do not explain the rationality that can be a reason to discuss more. All employees were of the opinion that things that are successful in America can never be successful in Italy especially in Matera. Chi was bit 
shocking but asked why, what's wrong with Matera. Employees said that most of the people in our company either American or others that can't get the business done. Chi called off the meeting and upgrade few things and went back to other assignment. Chi took a drive from Matera to Bari next morning.

\subsection{Chi'S Visit (Shanghai)}

Chi diverted his travelling plan and boarded a plane that was bound for Shanghai. He was not happy with the performance of two other offices and expecting something good in Shanghai office but did not get what he expected. He rather had more disappointment in this office. When he had meeting with them, most of employees were not cooperating with one another. In this meeting employees talked about people who should cooperate and were not cooperating with people. When Chi inquired about this from Wayne, he answered that this is happening since many years where some people don't seem to cooperate about with other colleagues. Wayne also complained about this cooperation as he already informed Chi few months back. Chi had a separate meeting with Wayne and asked him openly about the problem. At dinner between Wayne and Chi including some senior people told that they are not interested to continue work here. That was shocking for Chi but Wayne was confident that he has already decided about this change which they believed is going to be good one. Wayne told that people in this company are good but don't want to collaborate with each other. This is the reason that keeps the customers away from the company. Customers believe that service employees are not cooperating with technical issues and customer service is not good as it should be.

\subsection{Chi's Visit (Dubai)}

Chi landed in Dubai and did not want to see office before he checks the popular Burjull Khalifa and other Dubai attractions. He just wanted to be fresh out of the tensions that faced in three offices. Two days passed and now he decided to see the office. When he reached in office, Mr Ahmed received him and hosted a good breakfast with lot more extra things. When Chi watched to inquire about the progress, Ahmed said forget about the company, lets enjoy, fresh and will talk about the company later. So the meeting was arranged when Chi noticed that all employees were happy and were coming on their own timing and kept managing to check mobile phones after every 15 to 20 minutes. When chi started discussion with them Ahmed did not understand what he means. Perceived on his own way and communicated to employees. Ahmed answered all questions. Other employees were not interested to talk much on company issues. They said that they are happy and company will be good after some more development. Chi asked about the development but were unaware about the developments they maintained. Ahmed informed Chi that people execute company activities according to their own methods not American styles. Ahmed also informed Mr. Chi that things can only be done according to our own perceptions. But Ahmed suggested that some good people should be trained in America on some company issues and styles of work to familiarize about the company values.

\section{Tokyatech's Action Plan}

After fourteen hours flight from Dubai to NY, Chi went home and took a rest for two days. He did not want to go to office till he comes up with any plan. He contacted his best friends from corporate world and invited them to have a coffee chat at Starbuck in the crowded Manhattan. He just requested only few friends like Suzy (a retired corporate leader), Paul (a Senior Economist), and Sandy (a Professor of International Business). They all enjoyed a coffee and suddenly Chi said to all that he needs their help to put company on a right track. All of friends were very attentive and said yes what can we do for you buddy? Chi explained a situation and everything about a recent visits about all decentralized centers. He also told them about the progress during those days. They all had evaluated the options through great experience as knowledge scholars \& competitive leaders. They discussed to apply Jack's (Winning book) option specially 25 points, they evaluated Jim Collins philosophy of putting best people on biggest opportunities rather on problems and few other as business cases and changing management practices as needed. After huge discussion, they found consensus that all four heads of four units should travel to NY(Head office) and have a meeting with all Chi's friends and other trusted people to find out the best solution and put company on right track as it is mentioned in missions and visions of the company. He wants to continue collaboration in order to maintain a good rapport among all employees. He decided to keep all employees totally informed about the happenings of the company and sharing good things with other decentralized centers. He created a MN (Main Node) for LMSD-London, Matera, Shanghai and Dubai to be connected with employees every time to be familiar and connected all the time. A high level meeting was scheduled on the top floor of the head office with a beautiful view of La Guardia local airport near the office. All head of four centers reached to NY and required to report after having a rest of two days. Chi and his close friends had arranged a great management development programs by applying ODC model that can contribute to the purpose of four units. All four heads also brought the results of the survey that was conducted two months 
before after the visit of Mr. Chi. The interesting point and a convincing factor was that the survey was very similar to all points. Survey results were based on the qualitative approach to know how the diversity is and how are other initiatives that can be improved? It said that $40 \%$ executive responded that diversity program is not effective, $40 \%$ said it is some effective and $20 \%$ reached unsure about such program.

Table 1. Survey on HR \& management diversity

\begin{tabular}{ll}
\hline LONDON & \\
\hline HR \& Management & $20 \%$ \\
In-effective & $60 \%$ \\
Effective & $20 \%$ \\
Undecided & \\
MATERA & \\
HR & $50 \%$ \\
In-effective & $20 \%$ \\
Effective & $30 \%$ \\
Undecided & \\
SHANGHAI & \\
Management & \\
In-effective & $50 \%$ \\
Effective & $30 \%$ \\
Undecided & $20 \%$ \\
DUBAI & \\
HR \& Management & \\
In-effective & \\
Effective & $20 \%$ \\
Undecided & $60 \%$ \\
\hline
\end{tabular}

After evaluating such quick survey by four heads, Chi and his friends decided to apply any framework or model that best suits on such four units. Diversity programs are most successful in Dubai and London because of its diversified culture while Matera and Shanghai are culturally affected where corporate reforms can be decided to bring all four units at par of progress.

\subsection{Factors of diversified HR and Relationship Management}

Mr Chi wanted the company to perform at number one in all areas but had not enough support from some decentralized centers around the world. After all visits and meetings with HR heads, OD consultants, Marketing directors, Management philosophers and confidential employees, he had drawn a framework of diversified HR \& relationship Management that explains as the collaboration between HR \& Management visions of the company. He listed down many HR factors including some overlapping marketing factors. He believed that Management \& HR factors are supposed to be effective as desired. He took opinion from different HR managers \& marketing directors and found out that company needs special training programs to understand effective factors. He took another survey on the factors and listed down as effective as in first column and in-effective as shown in second column and some people remain undecided as shown in $3^{\text {rd }}$ column. After evaluating all such factors, he proposed a detailed training program for all centers. Proposing training was not first time initiative but this time was more rigorous based as to move in most disciplined manner. He found many points but following method was most effective in the situation. 
Table 2. Diversified HR \& relationship management

\begin{tabular}{llll}
\hline EFFECTIVE & IN-EFFECTIVE & UNDECIDED \\
\hline - & Proper training & & \\
- & Diversity importance & Lack of training & \\
- & Experience marketing & Less motivated employees & In-experienced \\
- & Employee branding & Lack of collaborative skills & Less exposure \\
- & Dealing with customers \& employees & Rude behaviors & Less \\
- & Collaboration among employees & Lack of understanding on the driven \\
- & Customer's comfortability & importance of diversity. & \\
- & Diversified culture, knowledge \& exposure & Lack of Employee branding & \\
\hline
\end{tabular}

Mr. Chi concluded by listing following questions \& factors.

- Which community \& customers we want to serve?

- Need to hire people according to the situation

- Training is must on few important aspects

- Tell them about organizational culture \& benefits of diversity

- Tell them about the success of diversity in other companies

- Tell them about diversified changes \& customers

- Tell them about organizational plan towards employee branding

- Tell them about Collaborative efforts

- $\quad$ Match the results (preview \& review)

- If results are same, factors are ineffective

- If results are good, factors are effective

- If results are very good then factors are excellent

After brainstorming and rational discussion, all members decided to learn ODC and instill the same to other members in the company. Later this must be applied in most effective manner as people may not realize what members realize about them. This is kind of secret change program that can be applied for the benefits of employees \& employer in particular.

The second phase was to train employees on the values of organization based on HR \& Management visions. Following was the second framework that was proposed in order to have an accurate training reform to put company on the right direction.

\subsection{Training on Values of Diversified HR and Relationship Management}

ODC stands for Organizational, Diversity and Cultural values

Diversity becomes valuable if ODC values are taught as they should be in the company. There are many things that can be bridged with diversity values. Diversity value can create a cordial atmosphere and collaborative work environment in particular. 
Table 3. Values of diversified HR \& relationship management model

\begin{tabular}{ll}
\hline DHR\&RM Model \\
\hline- & Organizational Values \\
$\circ$ & Total information with clarity concerns \\
$\circ$ & Making people realize about growth and targets \\
$\circ$ & Clarity on Visions to keep all employees on board. \\
- & Diversity Values \\
$\circ$ & Varied thoughts with quality ideas \\
$\circ$ & Building new \& standard collaboration \\
$\circ$ & Workforce readiness for new strategies \\
$\circ$ & Easy adoption of new changes \& developments \\
$\circ$ & Cordial working environment for all employees \\
$\circ$ & Update and market HR policies \\
- & Cultural Values \\
$\circ$ & Dealing employees the way they are \\
$\circ$ & Dealing customers the way they like to be \\
$\circ$ & Respecting employees the way they want to be \\
$\circ$ & Training employees the way they should be \\
$\circ$ & Coordinating employees the way they meant to be \\
$\circ$ & Helping employees the way they wish to be \\
$\circ$ & Helping customers the way they wish to be. \\
\hline
\end{tabular}

To achieve the value, organizations have two options either deal with cultural values or manage with diversity values. Cultural values can be effective in certain situations but diversity values will surely pay something special to company development. To achieve this, evaluate the survey, have people responded to diversity issues, apply DHR\&RM model, understand organizational values, win employees through cultural values and adopt diversity values to take a lead from competitors. Chi instructed Andrew, Giovanni, Wayne, and Ahmed about DHR\&RM Model and emphasized to have complete familiarity to apply on the company. Ahmed \& Wayne suggested that we need to train at least two more people from higher cadre to be trained with us and later we implement there in our offices. This point was well taken and all agreed on that and selected two more people from each decentralized centers. They started training. All of them decided to arrange a training in London office as a center point with some change. The training was focused on many points but DHR\&RM Model was highly kept in mind. All unit heads and others were told to apply DHR\&RM Model in proper manner. That means that no haste, we have to plan well so that execution can be done. More focus was on how you give total information to employees and keep them informed and in confidence. Start valuing your employees who will then value your plans in the organization. Chi and his friends prepared an Action Plan for 100 pages with 100 days deadlines to complete all required plan, training, and implementation. After 100 days training \& implementation, there will be a gap of 100 days. Chi and four heads will have a comparative analysis of all four units to evaluate who achieved more. Chi also promised a double bonus for all if implemented in the desired manner.

\section{Research Methodology and Clarity Note}

This case study approach was based on armchair case methodology with focus on qualitative aspects. This is specially designed for the purpose of HR, management, OD, International Business \& marketing students to make them understand the proposed frameworks as mentioned in different tables. The proposed frameworks are the primary source of authors' opinions, expertise and interest in case based approaches. TokyaTech is an imaginary company and used as technical company having decentralized centers around the world.

\section{Conclusion and Future Research}

This case study concludes on the practical implications of effective factors of HR diversity \& relationship Management that have been comprehended, imagined, aligned, analyzed and applied to support HR teaching. This is also concluded that such qualitative style case study will enhance practical exposure of business students. This further help students in intellectual capability of observing HR \& Management features of modern organizations. Further research can also be initiated on the application of frameworks or models as mentioned in this case. Further case studies can also be developed on similar lines of applying ODC values. 


\section{References}

Arthur, J. B. (1992). The link between business strategy and industrial relations systems in American steel minimills. Industrial and Labor Relations Review, 45(3), 488-506. http://dx.doi.org/10.1177/001979399204500306

Aryee, S. (1991). Creating a committed workforce: Linking socialization practices to business strategy. Asia Pacific Human Resource Management, 102-112. http://dx.doi.org/10.1177/103841119102900111

Buller, P. (1988). Successful partnerships: HR and strategic planning at eight top firms. Organisational Dynamics, 17, 27-42. http://dx.doi.org/10.1016/0090-2616(88)90017-4

Gennard, J., \& Kelly, J. (1995). Human resource management: The views of personnel directors. Human Resource Management Journal, 5(1), 15-32. http://dx.doi.org/10.1111/j.1748-8583.1994.tb00357.x

Jackson, S. E., \& Schuler, R. S. (1999). Understanding human resource management in the context of organizations and their environments. In R. S. Schuler \& S. E. Jackson (Eds.), Strategic HRM. Blackwell, Oxford.

Kurland, N. B., \& Egan, T. (1999). Public vs. private perceptions of formalization, outcomes and justice. Journal of Public Administration Research and Theory, 3, 437-580. http://dx.doi.org/10.1093/oxfordjournals.jpart.a024417

Muenjohn, N., \& Armstrong, A. (2007). Transformational leadership: The influence of culture on the leadership behaviors of expatriate managers. IJBI, 2(2), 265-283.

Shamir, B., House, R. J., \& Arthur, M. B. (1993). The motivational effects of charismatic leadership: A self-concept based theory. Organization Science, 4(4), 577-594. http://dx.doi.org/10.1287/orsc.4.4.577

\section{Copyrights}

Copyright for this article is retained by the author(s), with first publication rights granted to the journal.

This is an open-access article distributed under the terms and conditions of the Creative Commons Attribution license (http://creativecommons.org/licenses/by/3.0/). 